\title{
A CLINICAL STUDY OF GERIATRIC DERMATOSES
}

\author{
Preeja R', Priya Ashok², Joan Felicita Samson ${ }^{3}$ \\ 1 Junior Resident, Department of Dermatology and Venereology, Government Medical College, Trivandrum. \\ ${ }_{2}^{2}$ Assistant Professor, Department of Dermatology and Venereology, Government Medical College, Trivandrum. \\ 3Professor, Department of Dermatology and Venereology, Dr. Somervell Memorial CSI Medical College, Karakonam, Trivandrum.
}

\section{ABSTRACT}

\section{BACKGROUND}

Geriatric population is increasing worldwide. Hence, a proper understanding of geriatric skin disorders is important for a dermatologist. Though there are a large number of studies on the pattern of geriatric dermatoses, there is a scarcity of such studies in Kerala in the available literature.

Aims- To study the pattern of dermatoses in geriatric population and to analyse the association of common geriatric dermatoses with systemic illnesses.

\section{MATERIALS AND METHODS}

This was a descriptive study in which patients aged sixty years and above who attended the Geriatric Department of a tertiary care centre in Kerala was studied. Detailed dermatological examination was done and relevant laboratory investigations were done. Association of geriatric dermatoses with systemic illnesses was analysed.

\section{RESULTS}

Non-infective dermatoses outnumbered infective dermatoses. Xerosis was the commonest dermatosis. Glogau wrinkling scale was Grade III in the majority of patients. A statistically significant association of xanthelasma palpebrarum with dyslipidaemia and cherry angioma with diabetes was noted in the study.

\section{CONCLUSION}

Dermatological findings in geriatric population was universal in this study. This would necessitate the need for conducting dermatological clinics for these patients.

\section{KEYWORDS}

Geriatric Dermatoses, Glogau Scale.

HOW TO CITE THIS ARTICLE: Preeja R, Ashok P, Samson JF. A clinical study of geriatric dermatoses. J. Evolution Med. Dent. Sci. 2017;6(59):4338-4342, DOI: 10.14260/Jemds/2017/938

\section{BACKGROUND}

Ageing is a complex process that has been defined as the accumulation of molecular damage over time. Both intrinsic and extrinsic factors are responsible for ageing. ${ }^{1}$ The most obvious signs of ageing include atrophy, laxity, sagging, a multiplicity of pigmented blemishes and sparse grey hair. ${ }^{2}$ The common dermatoses prevalent in the geriatric age group include xerosis, asteatotic dermatitis, psoriasis, nonhealing ulcers, infectious diseases including bacterial, viral and fungal infections, parasitic infestations, immunobullous disorders like bullous pemphigoid, etc. ${ }^{3}$

Management of dermatoses in older population has emerged as an important area of consideration today. ${ }^{4}$ The pattern of skin disorders in elderly is quite different from that of youngsters.

Though there are a large number of studies on the pattern of geriatric dermatoses, there is a scarcity of such studies in Kerala in the available literature.

Financial or Other, Competing Interest: None.

Submission 19-06-2017, Peer Review 13-07-2017,

Acceptance 19-07-2017, Published 24-07-2017.

Corresponding Author:

Dr. Priya Ashok,

Assistant Professor

Department of Dermatology and Venereology,

Government Medical College, Trivandrum.

E-mail: priyaashok242@gmail.com

DOI: $10.14260 /$ jemds $/ 2017 / 938$
Hence, the present study was undertaken to study the pattern of geriatric dermatoses in our setting. The association of common geriatric dermatoses with systemic illness was also analysed.

\section{MATERIALS AND METHODS}

This was a descriptive study conducted in 275 patients aged 60 years and above who attended the Geriatric Clinic, Medical College, Thiruvananthapuram.

After taking an informed consent, patients were clinically evaluated with a detailed history and a complete physical examination, as per a detailed proforma. History included any dermatological complaints, systemic diseases, treatment, addictions, etc. Routine blood and urine examination, random blood sugar, liver and renal function tests and lipid profile were done in every patient. Other relevant investigations like scraping and $\mathrm{KOH}$ mount for fungus, skin biopsy for histopathological examination and direct immunefluorescence were done in relevant cases.

The data was entered in Microsoft Excel and analysed using the computer software, Statistical Package for Social Science (SPSS) version 17. The data was expressed in frequency and percentage. Descriptive statistics were used to analyse the data. The Chi-square test was used to assess statistical significance and a 'P' value of $<0.05$ was considered to be statistically significant. 


\section{RESULTS}

In our study, males slightly outnumbered females. Out of the 275 patients, there were 139 males (50.5\%) and 136 females (49.5\%).

\begin{tabular}{|c|c|c|}
\hline Gender & Frequency & Percentage \\
\hline Male & 139 & 50.5 \\
\hline Female & 136 & 49.5 \\
\hline Total & $\mathbf{2 7 5}$ & $\mathbf{1 0 0 . 0}$ \\
\hline \multicolumn{3}{|c|}{ Table 1 } \\
\hline
\end{tabular}

The majority of patients were in the 60 to 64 years age group (36\%). The oldest patient was an 88-year-old man.

The majority of the geriatric patients had no skin complaints (62.5\%). Generalised pruritus was the commonest skin complaint observed in 42 patients $(15.3 \%)$. 27 patients had pruritic skin lesions as the complaint (9.8\%). 22 patients complained of hyperpigmented skin lesions (8\%). 16 patients complained of hypopigmented skin lesions (5.8\%), 6 patients complained of depigmented skin lesions $(2.2 \%)$. Nonhealing ulcer was the complaint in 4 patients (1.5\%). 10 patients complained of burning pain in the oral cavity (3.6\%).

The most common systemic disease encountered was diabetes, present in 141 patients (51.3\%). Hypertension was the next common systemic disease, present in $35.6 \%$. Dyslipidaemia was present in $19.6 \%$. 35 patients had coronary artery disease (12.7\%).

\begin{tabular}{|c|c|c|}
\hline Systemic Disease & Frequency & Percentage \\
\hline Diabetes & 141 & 51.3 \\
\hline Hypertension & 98 & 35.6 \\
\hline Dyslipidaemia & 54 & 19.6 \\
\hline Coronary artery disease & 35 & 12.7 \\
\hline Cerebrovascular accident & 18 & 6.5 \\
\hline Bronchial asthma & 18 & 6.5 \\
\hline COPD & 10 & 3.6 \\
\hline Hypothyroidism & 16 & 5.8 \\
\hline Liver disease & 11 & 4.0 \\
\hline Renal disease & 11 & 4.0 \\
\hline Fever & 18 & 6.5 \\
\hline Epilepsy & 1 & 0.4 \\
\hline Pulmonary tuberculosis & 5 & 1.8 \\
\hline Psychiatric disease & 5 & 1.8 \\
\hline Peptic ulcer disease & 2 & 0.7 \\
\hline Malignancy & 3 & 1.1 \\
\hline \multicolumn{2}{|l|}{ Table 2 } \\
\hline
\end{tabular}

The most common general examination finding was pedal oedema in 43 patients (15.6\%). Pallor was the next common finding, observed in 37 patients (13.5\%).

Majority of patients had a normal BMI of 18.5 to 24.9 (54.9\%). 82 patients were overweight with a BMI of 25 to 29.9 (29.8\%). 25 patients (9.1\%) were obese with a BMI ranging from 30 to 34.9 .17 patients were underweight with a BMI under 18.5 (6.2\%).

In the majority of patients (89.8\%), Glogau wrinkling scale (figure 1) was grade III. The next common Glogau scale was grade IV (8\%). There were 6 patients with Grade II Glogau scale (2.2\%).
Xerosis was the most common dermatosis observed in the study, found in 151 patients (54.9\%). The next common dermatosis was idiopathic guttate hypomelanosis (36.7\%). The third common dermatosis was senile ichthyosis $(29.5 \%)$ (figure 2).

The common non-infective dermatoses observed in the study were xerosis (54.9\%), senile ichthyosis (29.5\%), dermatosis papulosa nigra (24\%) (figure 3), acrochordon (24.4\%), cherry angioma (17.1\%) (figure 4), seborrhoeic keratoses (17.8\%), colloid milia (13.1\%), macular amyloidosis (10.5\%), senile comedones (9.1), senile ecchymosis (4.7\%) (Figure 5), lichen simplex chronicus (4.7\%), fissure foot (12\%), non-healing ulcers (1.5\%), xanthelasma palpebrarum (figure 6), prurigo nodularis, psoriasis, bullous pemphigoid, longitudinal ridging of nails, oral submucosal fibrosis. Androgenic alopecia was seen in $25.8 \%$ of the geriatric population. Hirsutism was seen in $12.5 \%$ of the elderly females. 44 patients had eczemas $(16 \%)$. Among the eczemas, asteatotic eczema was the most common (5.8\%).

Pigmentary disorders were seen in 150 patients (54.5\%). Idiopathic guttate hypomelanosis was the commonest (36.7\%). Vitiligo was present in 8 patients $(2.9 \%)$. Lentigenes were present in 19 patients $(6.9 \%)$ and melasma was seen in 22 patients $(8 \%)$.

Among the infective dermatoses, fungal infection was the commonest (45.8\%). The next common infection was bacterial (6.9\%). Viral infections were seen only in 3 patients (1.1\%). Among the fungal infections, pityriasis versicolor was the most common, seen in 44 patients (16\%), followed by onychomycosis seen in 32 patients $(11.6 \%)$. Out of 19 patients with pyogenic infections, 9 had folliculitis, 5 had furuncle, 2 had carbuncle and 3 had impetigo.

The association of acrochordon with obesity was studied. The $\mathrm{p}$ value was 0.056 , and hence the association was not statistically significant. No statistically significant association of acrochordon with diabetes was observed in the study ( $p$ value-0.643).

A statistically significant association of cherry angioma with diabetes was observed in the study ( $p$ value- 0.002 ) (table 1). No statistically significant association of cherry angioma with obesity was found ( $p$ value-0.685). There was no statistically significant association of seborrhoeic keratoses with diabetes or obesity ( $p$ value 0.969 and 0.803 respectively).

\begin{tabular}{|c|c|c|c|c|c|c|}
\hline \multirow{2}{*}{$\begin{array}{c}\text { Cherry } \\
\text { angioma }\end{array}$} & \multicolumn{4}{|c|}{ Diabetes } & \multicolumn{2}{|c|}{ Total } \\
\cline { 2 - 7 } & Present & \multicolumn{2}{|c|}{ Absent } & \multicolumn{1}{|c|}{} \\
\cline { 2 - 7 } & $\mathbf{N}$ & $\mathbf{\%}$ & $\mathbf{N}$ & $\mathbf{\%}$ & $\mathbf{N}$ & $\mathbf{\%}$ \\
\hline Present & 34 & 24.1 & 13 & 9.7 & 47 & 17.1 \\
\hline Absent & 107 & 75.9 & 121 & 90.3 & 228 & 82.9 \\
\hline Total & $\mathbf{1 4 1}$ & $\mathbf{1 0 0}$ & $\mathbf{1 3 4}$ & $\mathbf{1 0 0}$ & $\mathbf{2 7 5}$ & $\mathbf{1 0 0}$ \\
\hline \multicolumn{7}{|c|}{ Table 3 } \\
\hline
\end{tabular}

$\chi^{2}=10.071 \mathrm{df}=1 \mathrm{p}=0.002$

A statistically significant association of xanthelasma palpebrarum with dyslipidaemia was obtained in our study ( $p$ value less than 0.001) (table 4). 


\begin{tabular}{|c|c|c|c|c|c|c|}
\hline Xanthelasma & \multicolumn{4}{|c|}{ Dyslipidaemia } & \multicolumn{2}{|c|}{ Total } \\
\cline { 2 - 7 } Palpebrarum & \multicolumn{2}{|c|}{ Present } & \multicolumn{2}{c|}{ Absent } & \multicolumn{2}{|c|}{} \\
\cline { 2 - 7 } & $\mathbf{N}$ & $\mathbf{\%}$ & $\mathbf{N}$ & $\mathbf{\%}$ & $\mathbf{N}$ & $\mathbf{\%}$ \\
\hline Present & 8 & 14.8 & 4 & 1.8 & 12 & 4.4 \\
\hline Absent & 46 & 85.2 & 217 & 98.2 & 263 & 95.6 \\
\hline Total & $\mathbf{5 4}$ & $\mathbf{1 0 0 . 0}$ & $\mathbf{2 2 1}$ & $\mathbf{1 0 0}$ & $\mathbf{2 7 5}$ & $\mathbf{1 0 0}$ \\
\hline \multicolumn{6}{|c|}{ Table 4 } \\
\hline
\end{tabular}

$\chi^{2}=14.609 \mathrm{df}=1 \mathrm{p}<0.001$

No statistically significant association of IGH and vitiligo with diabetes was present in our study ( $\mathrm{p}$ value- 0.089 and 0.316 respectively).
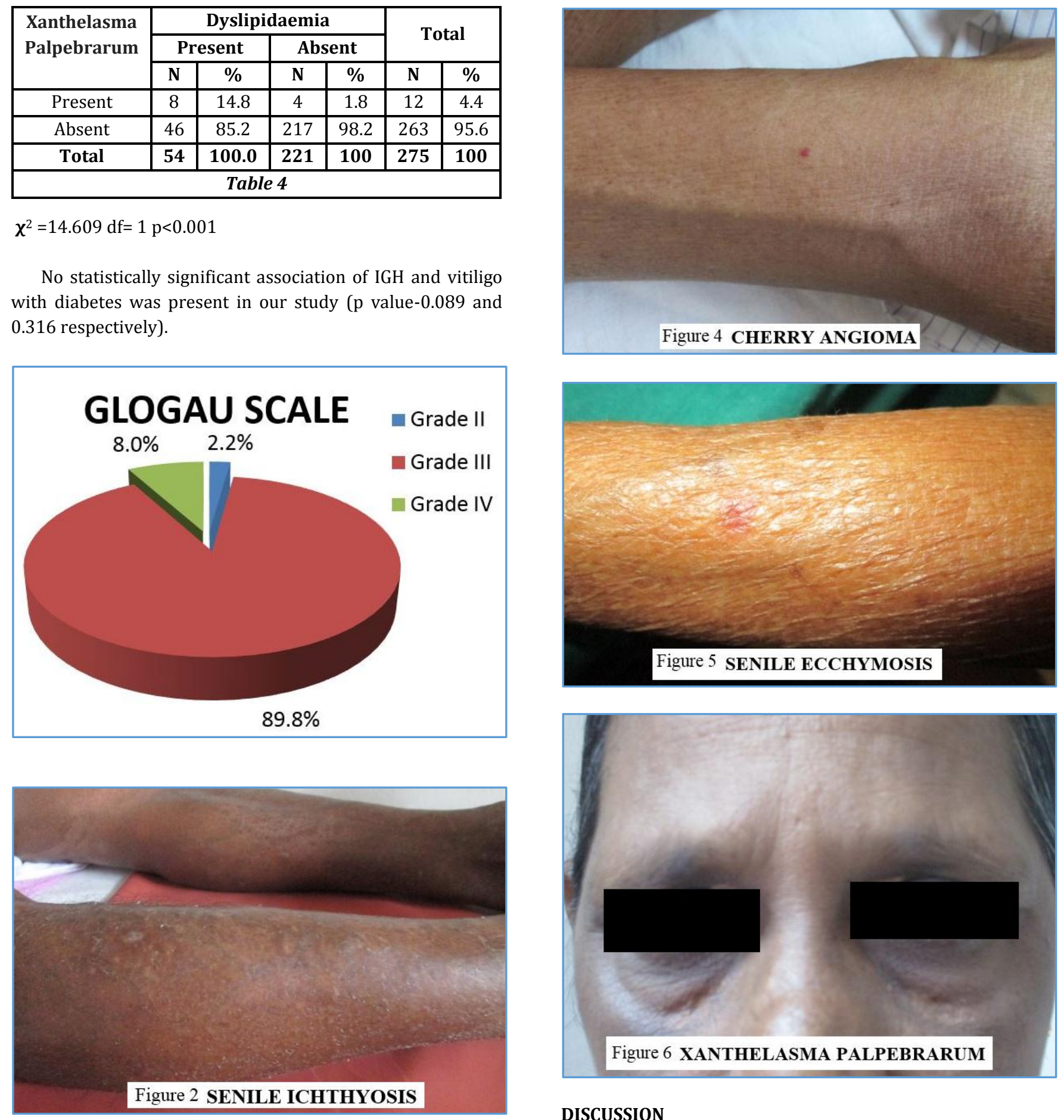

\section{DISCUSSION}

Geriatric patients 60 years and above attending the Geriatric Clinic were taken for the study. In the study on geriatric dermatoses in coastal Goa by Pavithra $S$ et al also, the lower limit of age was 60 years. ${ }^{5}$ Majority of the patients, were in the age group of $60-64$ years (36\%). The next common age group was 65 to 69 years (33.1\%). In a similar study by Patange SV and Fernandez RJ, the commonest age group was 55 to 64 years age group (66\%). ${ }^{6}$

In the study, out of the total 275 patients, 139 were male $(50.6 \%)$ and 136 were female $(49.5 \%)$. In the study by Patange SV, $63 \%$ were male and $37 \%$ were female. 6 of the 411 patients enrolled in the study in coastal Goa by Pavithra $S$ et al also, significant male preponderance was noted.

Skin complaints were not present in the majority (62.5\%). Generalised pruritus was the commonest skin complaint seen in 42 patients (15.3\%). This was significantly 
higher than that reported by a study in Goa by Pavithra S et al $(9.2 \%) .5$ In our study, 27 patients complained of pruritic skin lesions $(9.8 \%)$. This is in concordance with previous studies by Patange SV et al and Nair PA et al where also pruritus was the commonest dermatological complaint (78.5\%) observed. Nonhealing ulcer was the complaint in 4 patients (1.5\%). 3 out of them were diabetics and one was an old case of Hansen's disease with plantar ulcer.

The most common systemic disease in our study group was diabetes mellitus (51.3\%). Similar to our study, in a study of geriatric dermatoses in coastal Goa, diabetes was the commonest systemic disorder observed (16.8\%). ${ }^{5}$ However in a similar study in Gujarat by Nair PA et al, diabetics constituted only $14.4 \%$ of the study population. ${ }^{7}$ The higher incidence of systemic diseases in our study is due to the fact that we recruited our study population from the geriatric clinic, where elderly patients attend for treatment for their systemic ailments.

In our study, majority of patients had a normal BMI of 18.5 to $24.9(54.9 \%)$. This was in concordance with the study in urban slums in Guwahati district by Saikia AM and Mahanta N, where also majority had a normal BMI. 82 patients in our study were overweight with a BMI of 25 to 29.9 (29.8\%). 17 patients in our study were underweight with a BMI under $18.5(6.2 \%)$. In the study in urban slums in Guwahati district, a higher percentage of study group were underweight (12.2\%). ${ }^{8}$

In the majority of patients (89.8\%) Glogau wrinkling scale was grade III. Grade IV and II wrinkling was observed in $8 \%$ and $2.2 \%$ of study population. No patients had Grade I Glogau scale (figure I) thus the majority of patients in our study had high Glogau scales. This could be due to the fact that majority of our patients were manual labourers who used to work in the sun for a prolonged period of time

Every patient in our study were found to have at least one dermatoses on examination, though majority did not have any dermatological complaints. Non-infective dermatoses outnumbered infective dermatoses.

Xerosis was the commonest dermatosis observed in the study, found in 151 patients (54.9\%). This was in discordance with the observation by Patange et al where only a smaller percentage had xerosis $(7 \%){ }^{6}$ In a similar study conducted in Goa by Pavithra $\mathrm{S}$ et al also, the proportion of patients with xerosis was lower (6.6\%). ${ }^{5}$ The higher incidence of xerosis in our study could be due to the excessive use of soaps for bathing, bathing in hot water and limited use of emollients. Senile ichthyosis was noted in 81 patients in our study (29.5\%).

Dermatosis papulosa nigra was noted in $24 \%$ of study population. But in a study of skin disease of elderly in coastal Goa, only $5.3 \%$ of the study population had DPN. In the study, 49 patients had seborrhoeic keratoses (17.8\%). In the study by Patange et al $37.5 \%$ of population was found to have seborrhoeic keratosis. ${ }^{6}$ Acrochordon was observed in sixty-seven patients in our study $(24.4 \%)$. A similar observation was made in the study by Patange, where $24.5 \%$ of the geriatric population had acrochordon. ${ }^{6}$ Cherry angioma was noted in forty-seven patients (17.1\%). This was in concordance with the study by Pavithra $\mathrm{S}$ et al. ${ }^{5}$

Thirty-six patients in our study had colloid milia (13.1\%). The prevalence was much higher compared to a similar study in Goa (2.2\%). ${ }^{5}$ Twenty-nine patients were found to have macular amyloidosis in our study (10.5\%). The common bathing habits of our elderly population like the use of scrubs may be related to the high prevalence of macular amyloidosis.

Thirteen patients in the study had senile ecchymosis (4.7\%). A similar incidence was reported by Pavithra S et al. ${ }^{5}$ In the study by Patange et al a slightly higher prevalence of senile ecchymosis of $9 \%$ was reported. ${ }^{6}$ Thirteen patients in the study had lichen simplex chronicus (4.7\%). In the study by Patange et al a higher prevalence of LSC of $12 \%$ was reported. ${ }^{6}$ Four patients in the study had non-healing ulcers (1.5\%). Three patients were diabetics and one was an old case of Hansen's disease. In a study in Goa by Pavithra S et al, the prevalence of leg ulcers was higher $(6.6 \%) .{ }^{5}$

Twelve patients in the study were found to have xanthelasma palpebrarum (4.4\%). A much lower incidence of xanthelasma was reported in the study by Pavithra S et al $(1.4 \%) .^{5}$ This may be due to the higher incidence of systemic diseases like dyslipidaemia and diabetes.

Psoriasis was noted in 8 patients in this study (2.9\%). In the study by Patange et al, a higher percentage of $10.5 \%$ were reported to have psoriasis. ${ }^{6}$ Vesiculobullous disorders were seen only in one patient $(0.4 \%)$. This was lower compared to the study by Pavithra $\mathrm{S}$ et al (4.4\%). ${ }^{5}$ Longitudinal ridging of nails was the commonest nail disorder noted in our study (16.7\%). Similar to our study, among the nail disorders, longitudinal ridges (12.6\%) were the commonest in a study in Goa also. ${ }^{5}$

44 patients in the study had eczema (16\%). The incidence of eczemas in a study in coastal Goa was slightly higher $(19.2 \%) .^{5}$ The common pigmentary disorders encountered were idiopathic guttate hypomelanosis (36.7\%), vitiligo (2.9\%), lentigenes $(6.9 \%)$ and melasma $(8 \%)$. The reported prevalence of pigmentary disorders in our study was $46.5 \%$. In a study in coastal Goa the prevalence of pigmentary disorders was lower (5.8\%). ${ }^{5}$ In the study by Patange et al the incidence of IGH was lower, $24.5 \% .^{6} \mathrm{~A}$ still lower percentage of patients had IGH in a study in rural Gujarat. 7 patients in the study had vitiligo (2.9\%). The incidence of vitiligo, reported in the study by Patange et al was higher, seen in $19 \%{ }^{6}$

Fungal infections were seen in $45.8 \%$ of persons in our study. The common fungal infections noted in this study were pityriasis versicolor, intertrigo, tinea corporis, tinea cruris, onychomycosis, paronychia and oral candidiasis. Fungal infections were reported in $20.7 \%$ of population in a study conducted in Goa by Pavithra et al. ${ }^{5}$ The higher incidence of fungal infections reported in our study could be due to the higher prevalence of diabetes in our population group studied.

In our study, there was no statistically significant association of acrochordon with diabetes and obesity. This was also discordant to the findings of Akpinar $\mathrm{F}$ and Dervis E. ${ }^{9}$ The lack of association of acrochordon with diabetes and obesity in the study may be due to the fact that we have enrolled only elderly patients, which in turn is another independent risk factor for development of acrochordon. There was a statistically significant association of cherry angioma with diabetes in our study. In literature, increased numbers of cherry angioma have been recorded in diabetics, but this association is of doubtful significance. ${ }^{10}$ No statistically significant association of cherry angioma with obesity was observed in our study. No statistically significant 
association of seborrhoeic keratoses with diabetes or obesity was found in our study. We have taken only elderly individuals for the study, which in turn may be an independent risk factor for seborrhoeic keratosis. This may be the reason for lack of association with diabetes and obesity observed in the study.

A statistically significant association of xanthelasma palpebrarum with dyslipidaemia was obtained in the study. This was in concordance with a study conducted in a tertiary hospital in Delhi by Jain et al. ${ }^{11}$ No statistically significant association of IGH with diabetes was present in our study. No statistically significant association of vitiligo with diabetes was present in our study. In a study conducted by Gopal et al at Vishakapatnam, a statistically significant association of vitiligo with diabetes was observed. ${ }^{12}$ Lack of such association in our study could be due to the limited number of patients with vitiligo in our study.

\section{CONCLUSION}

Both intrinsic and extrinsic factors act together in producing the typical aged appearance of the skin. The presence of various systemic conditions like diabetes, obesity, hepatic and renal diseases also influence the pattern of dermatoses found in the geriatric population. The elderly are found to have increased incidence of various infective and noninfective dermatoses. Every geriatric patient in the study was found to have at least one dermatosis. Thus, skin disorders are very common in the elderly population. As geriatric population is increasing worldwide, a proper understanding of geriatric skin disorders is important for a dermatologist.

\section{REFERENCES}

[1] Durai PC, Thappa DM, Kumari R, et al. Aging in elderly: chronological versus photoaging. Indian J Dermatol 2012;57(5):343-52.

[2] Millington GWM, Brown RACG. Skin and skin disease throughout life. In: Burns T, Breathnach S, Cox N, et al. (eds). Rook's textbook of dermatology. $8^{\text {th }}$ edn. Vol 1. West Sussex: Blackwell Publishing Ltd; 2010: 821-9.
[3] Yaar M, Gilchrest BA. Aging of skin. In: Wolff K, Goldsmith LA, Katz SI, et al. (eds). Fitzpatrick's dermatology in general medicine. $7^{\text {th }}$ edn. Vol 1. New York: The McGraw-Hill Companies, Inc; 2008:963-73.

[4] Jafferany M, Huynh TV, Silverman MA, et al. Geriatric dermatoses: a clinical review of skin disease in aging population. Int J Dermatol 2012;51(5):509-22.

[5] Pavithra S, Shukla P, Pai GS. Cutaneous manifestations in senile skin in coastal Goa. Nepal J Dermatol Venereol 2010;9(1):1-6.

[6] Patange VS, Fernandez RJ. A study of geriatric dermatoses. Indian J Dermatol Venereol Leprol 1995;61(4):206-8.

[7] Nair PA, Bodiwala N, Arora TH, et al. A study of geriatric dermatoses at a rural hospital in Gujarat. J Indian Acad Geriatr 2013;9:15-9.

[8] Saikia AM, Mahanta NA. Study of nutritional status of elderly in terms of body mass index in urban slums of Guwahati city. J Ind Acad Geriatr 2013;9:11-4.

[9] Akpinar F, Dervis E. Association between acrochordons and the components of metabolic syndrome. Eur J Dermatol 2012;22(1):106-10.

[10] Mortimer PS, Burnand KG, Neumann HAM. Diseases of the veins and arteries. In: Burns T, Breathnach $\mathrm{S}$, Cox N, et al. (eds). Rook's textbook of dermatology. $8^{\text {th }}$ edn. Vol 3. West Sussex: Blackwell Publishing Ltd; 2010:12-21.

[11] Jain A, Goyal P, Nigam PK, et al. Xanthelasma palpebrarum-clinical and biochemical profile in a tertiary level hospital of Delhi. Ind J Clin Biochem 2007;22(2):151-3.

[12] Gopal KV, Rao GRR, Kumar YH, et al. Vitiligo: a part of a systemic autoimmune process. Indian J Dermatol Venereol Leprol 2007;73(3):162-5. 